\title{
Reversible severe deterioration of glycaemic control after withdrawal of metformin treatment
}

\author{
Z. Panossian • P. L. Drury • T. Cundy
}

Received: 17 July 2011 /Accepted: 23 September 2011 /Published online: 10 November 2011

(C) Springer-Verlag 2011

To the Editor: Metformin is the drug of choice in the management of type 2 diabetes mellitus. In clinical trials metformin is reported to reduce $\mathrm{HbA}_{1 \mathrm{c}}$ by $0.8 \%$ to $3.0 \%(8.8$ to $33 \mathrm{mmol} / \mathrm{mol})$ [1]. The majority of such trials were undertaken in patients with only moderately poor glycaemic control $\left(\mathrm{HbA}_{1 \mathrm{c}}<9.5 \%[<80 \mathrm{mmol} / \mathrm{mol}]\right)$. As the decrement in $\mathrm{HbA}_{1 \mathrm{c}}$ is related in part to pre-treatment glycaemia [2], the effects of metformin could be greater in those with poor control.

Cardiac, renal or hepatic dysfunction are considered contraindications to metformin because of the risk of lactic acidosis, and indeed metformin is often discontinued due to these concerns. There are few published data on what actually happens to glycaemic control when metformin is stopped. Here we describe a series of patients who experienced substantial increments in $\mathrm{HbA}_{1 \mathrm{c}}$ after stopping metformin, and report the effects of its later re-introduction.

We identified eight patients in whom discontinuation of metformin was followed by a marked deterioration of glycaemic control, defined as an increase of $\mathrm{HbA}_{1 \mathrm{c}}$ by $\geq 3 \%$ (33 $\mathrm{mmol} / \mathrm{mol}$ ) over 3 to 12 months. The patients were aged 50 to 87 years, with duration of diabetes of 7 to 23 years. Four patients were also being treated with sulfonylureas and three with insulin. Metformin (1.0 to $2.55 \mathrm{~g}$ daily) was stopped because of concern about renal

Z. Panossian $(\bowtie) \cdot$ P. L. Drury $\cdot$ T. Cundy

Auckland Diabetes Centre, Greenlane Clinical Centre,

PO Box 92189, Auckland 1142, New Zealand

e-mail: ZavenP@adhb.govt.nz

T. Cundy

Department of Medicine, Faculty of Medical and Health Sciences,

University of Auckland,

Auckland, New Zealand function (five patients), and cardiac function, hepatic function or side effects (one each).

We reviewed each case to consider whether metformin was truly contraindicated. We estimated GFR using the Cockcroft-Gault equation [3]. All patients gave informed consent to restarting metformin and all investigations were carried out in accordance with the Declaration of Helsinki as revised in 2000 (http:www.wma.net/e/policy/b3.htm).

In the 3 to 12 months after discontinuation of metformin, the mean increment in $\mathrm{HbA}_{1 \mathrm{c}}$ was 5.7 percentage points $(62.7 \mathrm{mmol} / \mathrm{mol})$, ranging from 3.5 to 8.9 percentage points $(38-97 \mathrm{mmol} / \mathrm{mol})(p<0.001)$. A mean weight gain of $2.6 \mathrm{~kg}$ was also observed. In the patients with concerns about renal function, the estimated GFR remained stable at $\geq 30$ (range 32-79) $\mathrm{ml} \mathrm{min}^{-1}$ $1.73 \mathrm{~m}^{-2}$. One patient had compensated Child grade A cirrhosis; the patient with cardiac disease had stable New York Heart Association grade II failure. In each of these cases we considered it safe to re-introduce metformin at the same dose as that used previously. The patient with side effects was able to tolerate a reduced dose. After re-introducing metformin, the mean $\mathrm{HbA}_{1 \mathrm{c}}$ decreased in seven of the eight patients over the following 4 to 12 months. The mean change was -4.3 percentage points $(-47 \mathrm{mmol} / \mathrm{mol})$, ranging from $\mathrm{HbA}_{1 \mathrm{c}}$ $12.4 \%$ to $8.1 \%(112$ to $65 \mathrm{mmol} / \mathrm{mol})(p=0.007)$. The range of change was +1.5 to -8.3 percentage points $(16.5$ to $-91 \mathrm{mmol} / \mathrm{mol}$ ) (Fig. 1a, b).

After withdrawal of metformin, glycaemic control in these patients deteriorated dramatically. The mean increment in $\mathrm{HbA}_{1 \mathrm{c}}$ of 5.7 percentage points $(62.7 \mathrm{mmol} / \mathrm{mol})$ suggests that the average plasma glucose increased by $>10 \mathrm{mmol} / \mathrm{l}$. Proof that withdrawal of metformin was responsible for this increase came from observing the effects of re-introduction, with the change seen in $\mathrm{HbA}_{1 \mathrm{c}}$ proving to be largely reversible. Surprisingly little has been written about what 

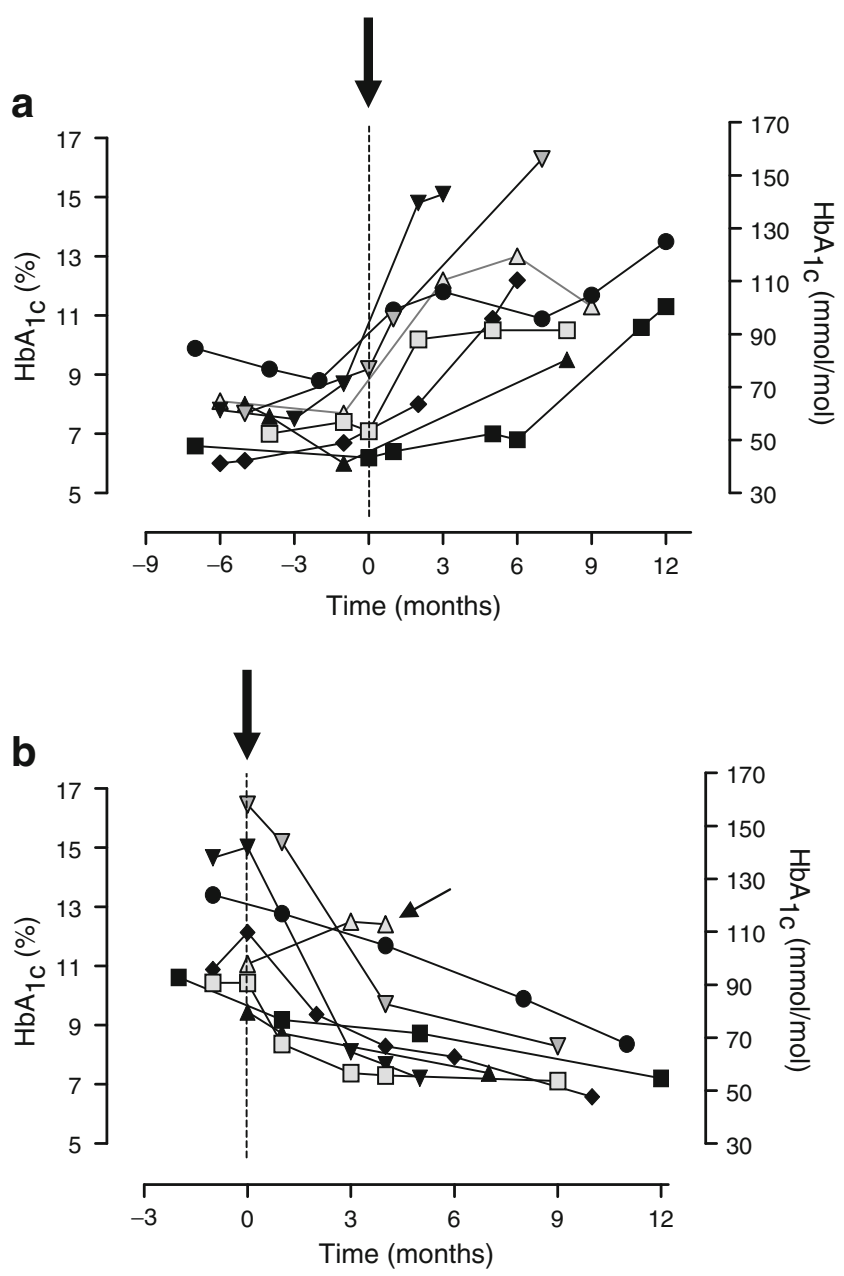

Fig. 1 Changes in $\mathrm{HbA}_{1 \mathrm{c}}$ in relation to metformin withdrawal (a) and re-introduction (b) in eight participants (four men, four women). Time-point of withdrawal or re-introduction was at month zero (large arrows and dotted lines). Sequential measurements for up to 1 year afterwards are shown. The small arrow (b) indicates the only patient in whom no reduction of $\mathrm{HbA}_{1 \mathrm{c}}$ was noted

happens to glycaemic control when metformin is discontinued, but one study of patients treated with insulin and metformin reported a $50 \%$ increase in insulin requirements when metformin was withdrawn [4].

The changes we observed are much greater than might have been expected. Kimmel et al. [1] reviewed the efficacy of metformin monotherapy in randomised controlled trials. In 2,876 patients the placebo-adjusted absolute percentage reduction in $\mathrm{HbA}_{1 \mathrm{c}}$ of metformin therapy ranged from $0.8 \%$ to $3.0 \%$ ( 8.8 to $33 \mathrm{mmol} / \mathrm{mol}$ ). However, in clinical trials the decrement in $\mathrm{HbA}_{1 \mathrm{c}}$ is in part related to pretreatment fasting blood glucose and $\mathrm{HbA}_{1 \mathrm{c}}$ [2]. Thus the real-life effects of metformin could be greater than the trials suggest (unless there is substantial beta cell failure, which may have been the case in the patient whose $\mathrm{HbA}_{1 \mathrm{c}}$ did not fall on re-introduction of metformin). Another factor likely to be relevant is that renal function was impaired in most of our patients; indeed, this was the main reason for withdrawal of treatment. Metformin is excreted unchanged, so delayed renal clearance could have contributed to its unanticipated efficacy [5]. Genetic variation may also determine differences in response to metformin [6].

Phenformin, metformin's sister drug, was introduced in 1957, but withdrawn in 1978 after being linked to severe lactic acidosis. Although metformin and phenformin have different structures, pharmacokinetics and metabolism, the spectre of lactic acidosis still influences recommendations on whether to prescribe metformin or not. However, there is little convincing evidence that metformin causes lactic acidosis in the absence of conditions predisposing to hypoxia or decreased tissue perfusion. In a recent review, pooled data from 347 studies featured no cases of lactic acidosis in over 70,000 patient-years of metformin use (including patients with mild-to-moderate renal impairment). The upper confidence limit for the incidence of lactic acidosis (per 100,000 patient-years) was 4.3 in the metformin group and 5.4 in the non-metformin group. Thus there was little evidence that metformin is associated with an increased risk of lactic acidosis compared with other oral hypoglycaemic treatments [7].

Renal impairment is common in patients with type 2 diabetes, but the point at which metformin becomes unsafe is still being debated; moreover, there is no good evidence base from which to make firm recommendations. The emerging consensus is that, provided renal function is checked regularly and metformin withheld if renal function deteriorates acutely, the benefits in patients with moderate renal impairment (estimated GFR $30-60 \mathrm{ml} \mathrm{min}^{-1} 1.73 \mathrm{~m}^{-2}$ ) probably outweigh the risks [8]. This is important, as metformin is associated with risk reductions of $42 \%$ for diabetes-related death and $36 \%$ for all-cause mortality [9]. Cardiac failure and chronic liver disease are also cited as contraindications to metformin, but views on these too are being revised. In patients with heart failure and type 2 diabetes, metformin is associated with lower mortality rates [10]. Similarly, metformin may benefit patients with non-alcoholic fatty liver disease.

Our observations indicate that glycaemic control can deteriorate markedly on metformin withdrawal. While debate continues about the indications for withdrawal, we recommend caution before discontinuing metformin, and would stress the need to ensure that there is a genuine contraindication and to consider whether withdrawal can be only temporary. We acknowledge that our patients were being closely followed at a specialist centre, and that the balance of risks and benefits may be different in similar patients treated in the community without such close supervision. 
Contribution statement We confirm that all authors reviewed and analysed the data, wrote, reviewed and edited the manuscript, contributed to discussion, and gave approval of the final version.

Duality of interest The authors declare that there is no duality of interest associated with this manuscript.

\section{References}

1. Kimmel B, Inzucchi SE (2005) Oral agents for type 2 diabetes: an update. Clin Diabetes 23:64-76

2. DeFronzo RA, Goodman AM, the Multicenter Metformin Study Group (1995) Efficacy of metformin in patients with non-insulin-dependent diabetes mellitus. $N$ Engl J Med 333:541-549

3. Rostoker G, Andrivet P, Pham I, Griuncelli M, Adnot S (2007) A modified Cockcroft-Gault formula taking into account the body surface area gives a more accurate estimation of the glomerular filtration rate. J Nephrol 20:576-585
4. Wulffelé MG, Kooy A, Lehert P et al (2002) Discontinuation of metformin in type 2 diabetes patients treated with insulin. Neth J Med 60:249-252

5. Scheen AJ (1996) Clinical pharmacokinetics of metformin. Clin Pharmacokinet 30:359-371

6. The GoDARTS and UKPDS Pharmacogenetics Study Group and the Wellcome Trust Control Consortium (2011) Common variants near ATM are associated with glycemic response to metformin in type 2 diabetes. Nature Genet 43:117-121

7. Salpeter SR, Greyber E, Pasternak GA, Salpeter EE (2010) Risk of fatal and nonfatal lactic acidosis with metformin use in type 2 diabetes mellitus. Cochrane Database Syst Rev (4):CD002967. doi:10.1002/14651858.CD002967.pub4

8. Lipska KJ, Bailey CJ, Inzucchi SE (2011) Use of metformin in the setting of mild-to-moderate renal insufficiency. Diabetes Care 34:1431-1437

9. United Kingdom Prospective Diabetes Study (UKPDS) Group (1998) Effect of intensive blood-glucose control with metformin on complications in overweight patients with type 2 diabetes (UKPDS 34). Lancet 352:854-865

10. Eurich DT, McAlister FA, Blackburn DF et al (2007) Benefits and harms of antidiabetic agents in patients with diabetes and heart failure: systematic review. BMJ 335:497-506 